\title{
Severe Posterior Infra-occlusion on a Young Girl Posing a Diagnostic Challenge- Review and Report of a Case of Primary Failure of Eruption
}

\author{
Mirna Awad ${ }^{1}$, Lana Dalbah ${ }^{1}$, M Srirengalakshmi $^{2}$, Adith Venugopal $^{2}$, and Nikhilesh Vaid ${ }^{1}$ \\ ${ }^{1}$ European University College \\ ${ }^{2}$ Saveetha University Saveetha Dental College
}

December 11, 2021

\begin{abstract}
Primary failure of eruption is characterized by a non-syndromic eruption failure of permanent teeth in the absence of any mechanical obstruction. Applying orthodontic traction to teeth affected by PFE will not be successful and may cause ankylosis. This correspondence reviews and demonstrates the treatment of a case of PFE.
\end{abstract}

Title

Severe Posterior Infra-occlusion on a Young Girl Posing a Diagnostic Challenge- Review and Report of a Case of Primary Failure of Eruption

Author Details

1. Mirna G Awad, MScFaculty, European University College, DHCC, Dubai, UAE. Email: mirna.george@euc.ac.ae

2. Lana Dalbah, MSc,Assistant Professor, European University College, DHCC, Dubai, UAE. Email: ldalbah@gmail.com

3. M. Srirengalakshmi, BDS, MDS.

Assistant Professor, Department of Orthodontics,

Saveeta Dental College, Tamil Nadu, India.

E mail- rengalakshmi1910@gmail.com

Adith Venugopal, BDS, MS, PhD.

Associate Professor, Department of Orthodontics,

Saveetha Dental College, Saveetha Institute of Medical and

Technical Sciences, Saveetha University, Chennai, India;

Assistant Professor, Department of Orthodontics,

University of Puthisastra, Phnom Penh, Cambodia

E mail: avenugopal@puthisastra.edu.kh

Nikhilesh R Vaid BDS, MDS, Ph.D. 
Professor and Vice Dean,

European University College, DHCC, Dubai, UAE.

E mail- orthonik@gmail.com

Corresponding author

Adith Venugopal, BDS, MS, PhD., FDSRCS.

Associate Professor, Department of Orthodontics,

Saveetha Dental College, Saveetha Institute of Medical and

Technical Sciences, Saveetha University, Chennai, India;

Assistant Professor, Department of Orthodontics,

University of Puthisastra, Phnom Penh, Cambodia

E mail: avenugopal@puthisastra.edu.kh

Data Availability Statement

The data used to support the findings of this study are included within the article.

\section{Funding Statement}

No funding received for this study

Conflict of interest disclosure

The authors declare no conflict of interest

Ethics approval statement

This study did not require an ethical approval from any review board.

Patient consent statement

The signed consent form is available with the principal author

Permission to reproduce material from other sources

$\mathrm{N} / \mathrm{A}$

Clinical trial registration

$\mathrm{N} / \mathrm{A}$

\section{Author Contributions}

Mirna G Awad and Lana Dalbah treated the case. M. Srirengalakshmi was involved in writing the case report. Adith Venugopal and Nikhilesh Vaid were involved in supervising, diagnosing, treatment planning of the case and proofreading the manuscript.

\section{Key Clinical Message}

Cases with failure of eruption are difficult to diagnose. Precious time must be spent observing how teeth present and respond during treatment. An underlying aetiology must be considered when comparing PFE, MFE, and impactions. Applying orthodontic traction to teeth impacted by PFE will not work and may develop ankylosis.

\section{Abstract}


Primary failure of eruption is characterized by a non-syndromic eruption failure of permanent teeth in the absence of any mechanical obstruction. Applying orthodontic traction to teeth affected by PFE will not be successful and may cause ankylosis. This correspondence reviews and demonstrates the treatment of a case of PFE.

\section{Keywords}

Primary failure of eruption; PFE; Mechanical failure of eruption; infraocclusion.

\section{Introduction}

Tooth eruption is a localized event that is genetically predetermined and occurs at a chronologically predetermined time. Eruption of permanent teeth is usually expedited by resorption of the overlying bone, primary tooth root and alveolar mucosa. ${ }^{1,2}$

When a tooth does not erupt into the oral cavity, the failure of its eruption can be attributed to a plethora of factors. Some of the commonly encountered factors include mechanical obstruction that include other teeth, calcifications in the surrounding bone, ${ }^{3}$ few habits like thumb or digit sucking, etc., conditions in which there is a fusion of the cementum to the adjacent bone resulting in ankyloses which prevents further eruption of the affected tooth. Usually if the cause is an obstruction, eruption usually resumes once the interference is removed..$^{3,1}$

Primary failure of eruption (PFE) was originally described by Proffit and $\mathrm{Vig}^{4}$ and is characterized by a non-syndromic eruption failure of permanent teeth in the absence of any mechanical obstruction.

\subsection{Features of PFE:}

The characteristic features of this condition $\operatorname{are}^{5-10}$

- History - There is no close familial or systemic association. However mutation in parathyroid hormone receptor 1 (PTH1R) has been associated.

- Clinical sign - Infra-occlusion of the affected teeth, involved teeth may erupt partially and cease in eruption, posterior open bite accompanying normal vertical facial growth and inability to move affected teeth orthodontically.

- Site of involvement - Posterior teeth are more frequently involved than the anterior teeth; usually all teeth distal to the most mesial affected tooth get affected; deciduous as well as permanent molars are likely to be involved and usually presents unilaterally.

- Gender predilection of Male: Female of 1: 2.25

- Radiographic sign: Resorption chimneys, which are enlarged bony crypts around the tooth-germ crowns formed due to resorption of the alveolar process are seen. Ankylosis may be a secondary feature.

Sylvia A and Frazier Bowers ${ }^{11}$ have categorized the different types of eruption failures. (Figure 1). There appears to be a subtle difference between the different types and definitive diagnosis is usually possible with other aids such as genetic linkage analysis. Though PFE appears as a complete failure of eruption without a distinct local or systemic etiology, mutations in parathyroid hormone receptor 1 (PTH1R) have been identified in several familial cases. ${ }^{5}$

A further clinical analysis revealed two types of non syndromic PFE : type I and type II, with both types primarily affecting the posterior segments, either unilaterally or bilaterally. Greater eruption potential of the most distal tooth affected with PFE delineates type II from type I. $^{8}$ It is not clear whether specific phenotypes are associated with distinct genetic mutations or represents the broad spectrum associated with PTH1R but it is well established that despite clinical severity or type, PFE does not respond to orthodontic force. $^{8-10}$

Decker et al.${ }^{12}$ genotyped 8 affected and 4 unaffected members in a three generation study on a German family. He found an autosomal dominant trait and mapped two regions with a maximumlod score of 2.41 , on chromosome 3p24.3-p14.3 and 13q31.3-q33.1 through parametric linkage analysis. 


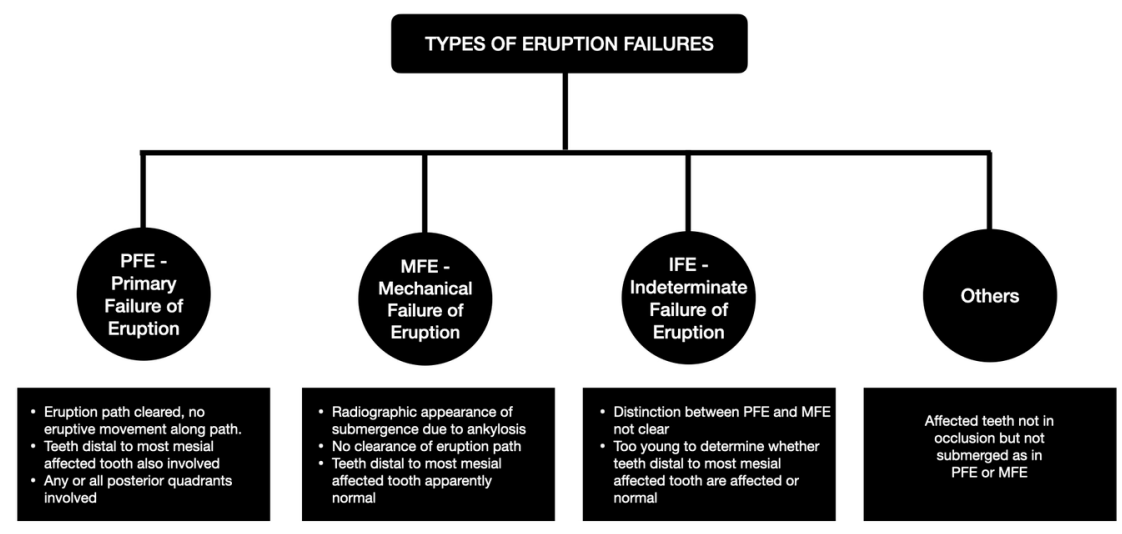

Figure 1: Types of eruption failures.

\subsection{Pathogenesis of PFE}

Regulatory events of tooth eruption are confined to the dental follicle region that envelop the unerupted tooth. Molecular events during the active eruptive phase of tooth movement can be broadly approached as genetic and proteomic events. These control the critical pathways of osteoclastogenesis and osteogenesis, which are imperative for eruption. Despite the huge clinical interest behind PFE, the core pathogenic mechanisms are yet to be deciphered. Most of the research pertain to assessment of specific genes involved. Many studies indicate mutation in the PTH1R gene, and about 51 mutations of the PTH1R gene have been reported till date. ${ }^{8,13,14,15,16}$ Transitory alteration to RANKL functions during the initial stage of dental root elongation and tooth eruption have also been reported in mouse models of PFE. ${ }^{17}$ In-depth analysis of chronological regulation and spatial localization of genes is key for improved understanding. Also, validation of the protein expression is essential for derivation of therapeutic interventions.

Other risk factors that have been consistently reported are a strong family history of PFE in $10 \%$ to $40 \%$ of PFE. Presence of virus in nerve tissues in the perifollicular region have also been studied, but disregarded due to lack of evidence. ${ }^{8}$

\subsection{Treatment options}

Treatment of patients with eruption failures can often be challenging. An interdisciplinary approach is required when considering the management of this rare condition. The various treatment options include: ${ }^{18,19,20,21}$

Accept the infra occlusion.

Restorative correction of the occlusion once growth has ceased.

Coronal build-up or onlay of the affected teeth.

A removable prosthesis over the affected teeth.

Extraction of affected teeth and prosthetic replacement.

Surgical repositioning of the affected area with a segmental osteotomy once growth has ceased, although limited success has been reported using this approach

Exposing and bonding teeth affected by PFE is not recommended as treatment with orthodontic forces has been suggested to lead to localised ankylosis. 


\section{Case History and Diagnosis}

A 13- year-old girl reported to us with multiple spaces between her front teeth and complained of difficulty in chewing. Clinical examination revealed a lack of lip fullness, bilateral posterior open bite with multiple submerged and infra-occluded posterior teeth. All the permanent teeth except for the upper left second premolar were seen intra-orally. Orthopantomogram (OPG) X-ray revealed infra-occluded first molars on all quadrants without any mechanical obstruction except for the second quadrant where in it seemed that an unerupted retained second deciduous molar was obstructing the eruption of an impacted second premolar and infra-occluded first molar. None of the infra-occluded or impacted teeth showed any radiological signs of ankylosis. (Figure 2)

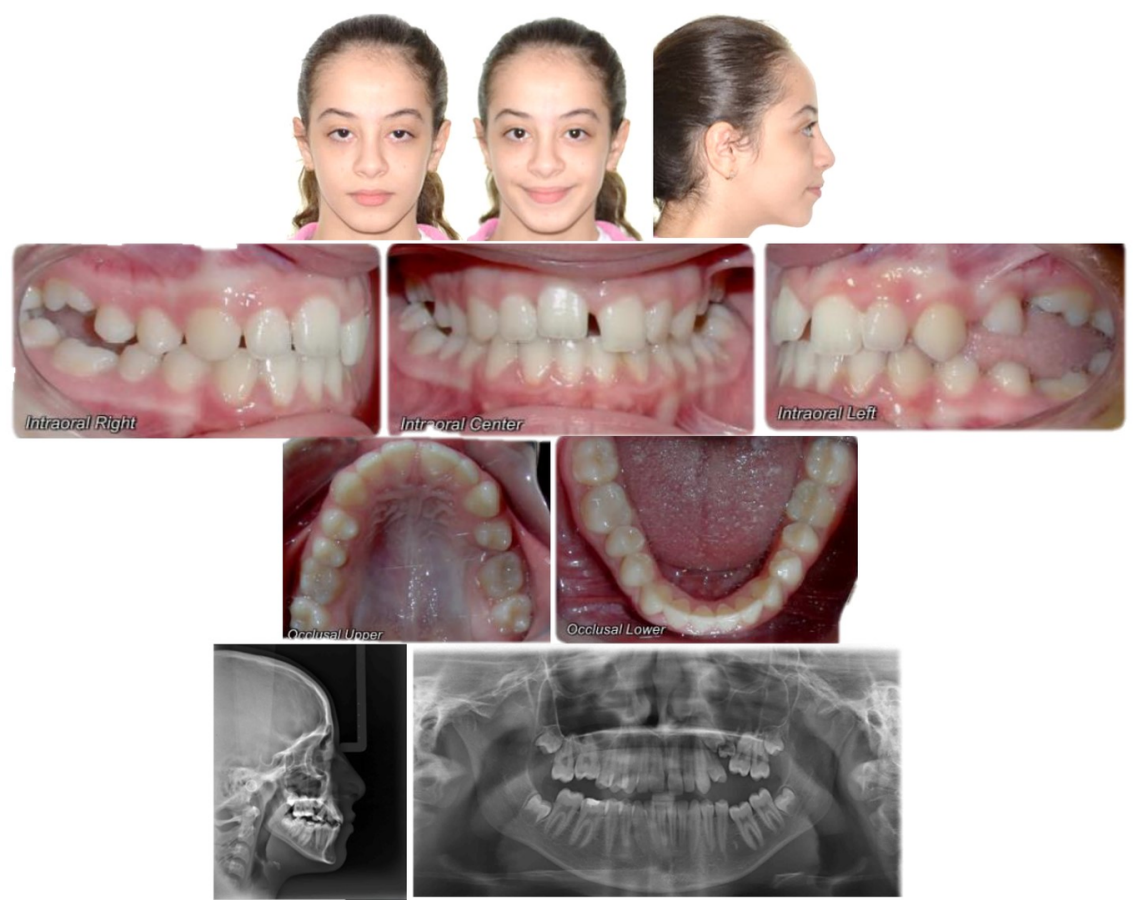

Figure 2: Initial treatment records with radiographs.

There was no significant underlying medical history. No one in her family had a history of unerupted teeth. She demonstrated a Class I malocclusion with a convex profile. The patient reported no significant or unusual variations in the eruption pattern and the eruption timings of her teeth on both sides. (Table 1) A further periapical radiograph confirmed normal periodontal ligament space and complete root formation of all her infra-occluded and impacted teeth. No relevant bone pathology was evident either. (Figure 3) Correlating the above clinical findings and radiological findings, a provisional diagnosis of eruption failure was made. Since there was no history or any other syndromic or familial involvement a therapeutic diagnostic approach was followed during the treatment.

Table 1 Cephalometric analysis

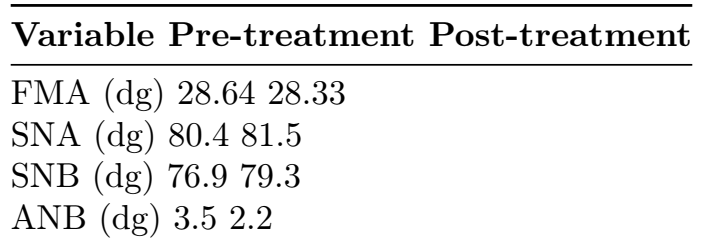


Variable Pre-treatment Post-treatment

IMPA (dg) 86.1677 .5

U1-SN (dg) 98.32106 .18

NLA (dg) 95.3595.98

INTERINCISAL ANGLE (dg) 132.76134 .54

RICKETT'S E LINE (mm) $0.26-1.00$
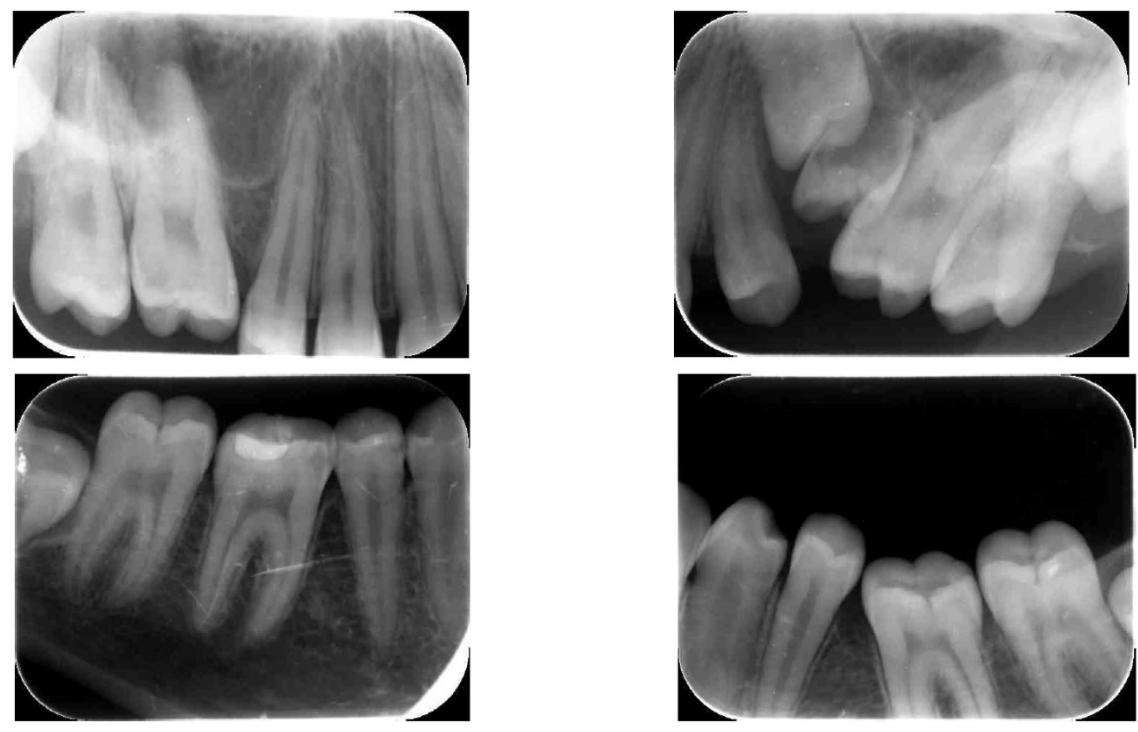

Figure 3: Periapical radiograph confirming normal periodontal ligament space and complete root formation of all her infra-occluded and impacted teeth.

\section{Treatment Plan and Progress}

Due to the presence of multiple spaces in the anterior region, and a mechanical obstruction in the form of an unerupted retained second deciduous molar on the second quadrant, it was decided to use a fixed orthodontic appliance to close the anterior spaces and get the impacted \#25 into occlusion without involving the first molars in the continuous arch.

A wait and watch approach was implemented wherein initially all the molars would be aligned without creating any extra space. If the molars would be unresponsive to the initial orthodontic forces, extraction of all first molars would be performed following which the left upper deciduous second molar would be extracted and all the spaces would be closed by protracting the second molars. At this point, it is assumed that extraction of the left upper deciduous second molar should be able to clear the path for eruption for the second premolar.

This case was treated using $0.022 " \times 0.028$ " slot pre-adjusted edgewise appliances with MBT prescription. Initial levelling was performed to align the arches and get the molars to the occlusal level. Initially the molars were not included into the main arch with the fear of further increasing the posterior open bite. Lingual buttons were placed on the buccal surfaces of the first molars and intermaxillary elastics $1 / 82 \mathrm{Oz}$ were used from the upper molars vertically to the lower molars in order to extrude them. (Figure 4) 


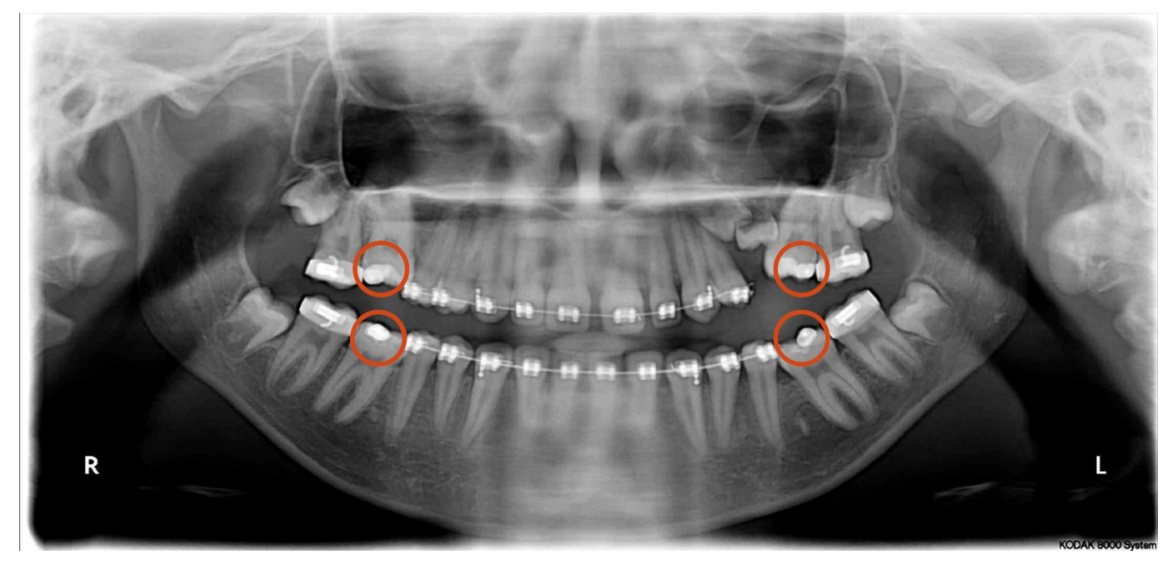

Figure 4: OPG showing four lingual buttons on the infra-occluded first molars for inter-arch traction using inter-maxillary elastics

Unfortunately, even after six months of levelling using a sequence of NiTi archwires, no change in the position of the molars were noticed.

It was then decided to extract all the first molars and the deciduous second molar on the upper left quadrant (for unhindered eruption of the \#25) and to protract the second molars into the extraction spaces.

After waiting for a couple of months, when the \#25 showed no signs of eruption, it was decided to extrude it orthodontically. A lingual button was placed on the exposed surface of the $\# 25$ and a power chain was tied from the button onto a stiff upper base arch wire (0.019" x 0.025 " SS) in order to provide vertical traction. (Figure $5 \mathrm{c}, \mathrm{d}, \mathrm{e})$

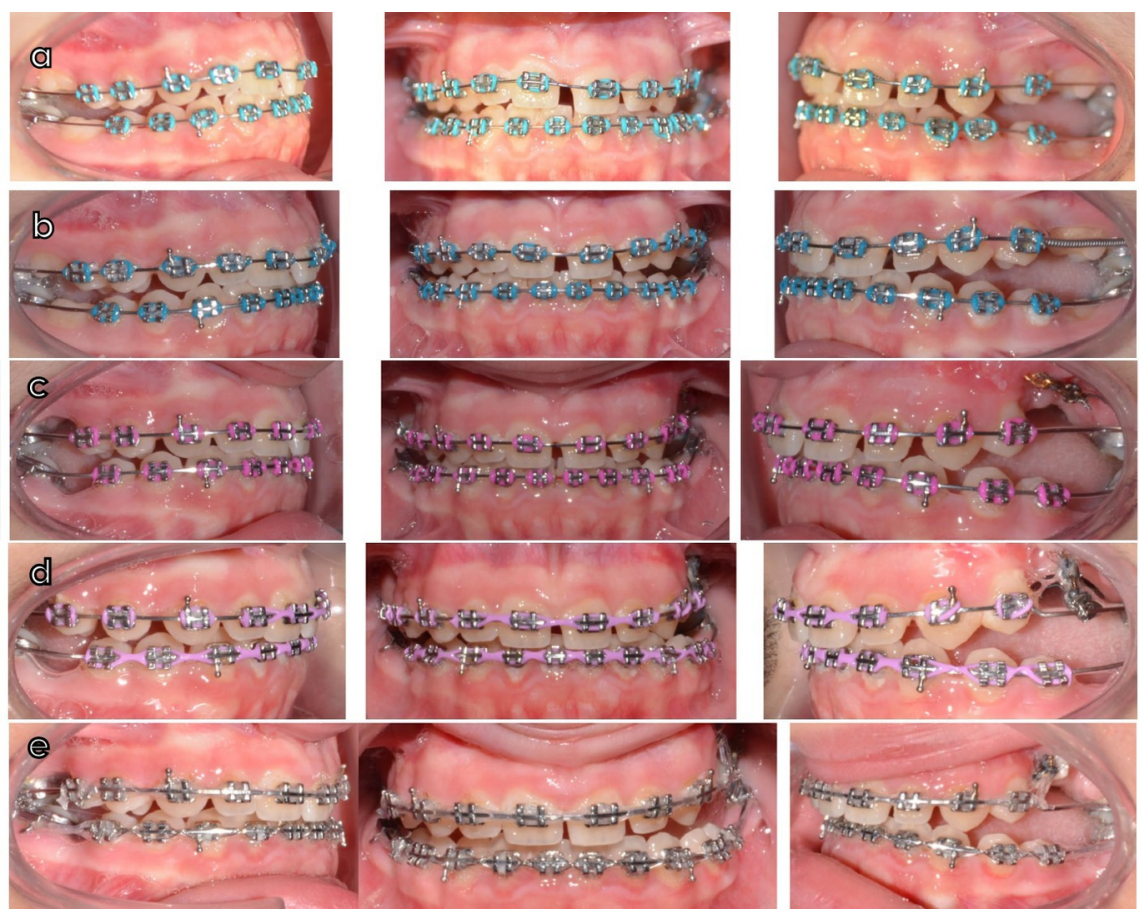

Figure 5: Treatment progress pictures. a,b: Before extraction of first molars; c,d,e: After 


\section{extraction of first molars.}

The impacted \#25 responded to the orthodontic force and began moving occlusally. The second molar on the right side was responding well to orthodontic protraction but the second molar on the left side was not. After 12 months of active treatment, both upper and lower second molars on the right side were successfully protracted, but the spaces on the left remained the same. (Figure $6 \mathrm{a}, \mathrm{b}$ )

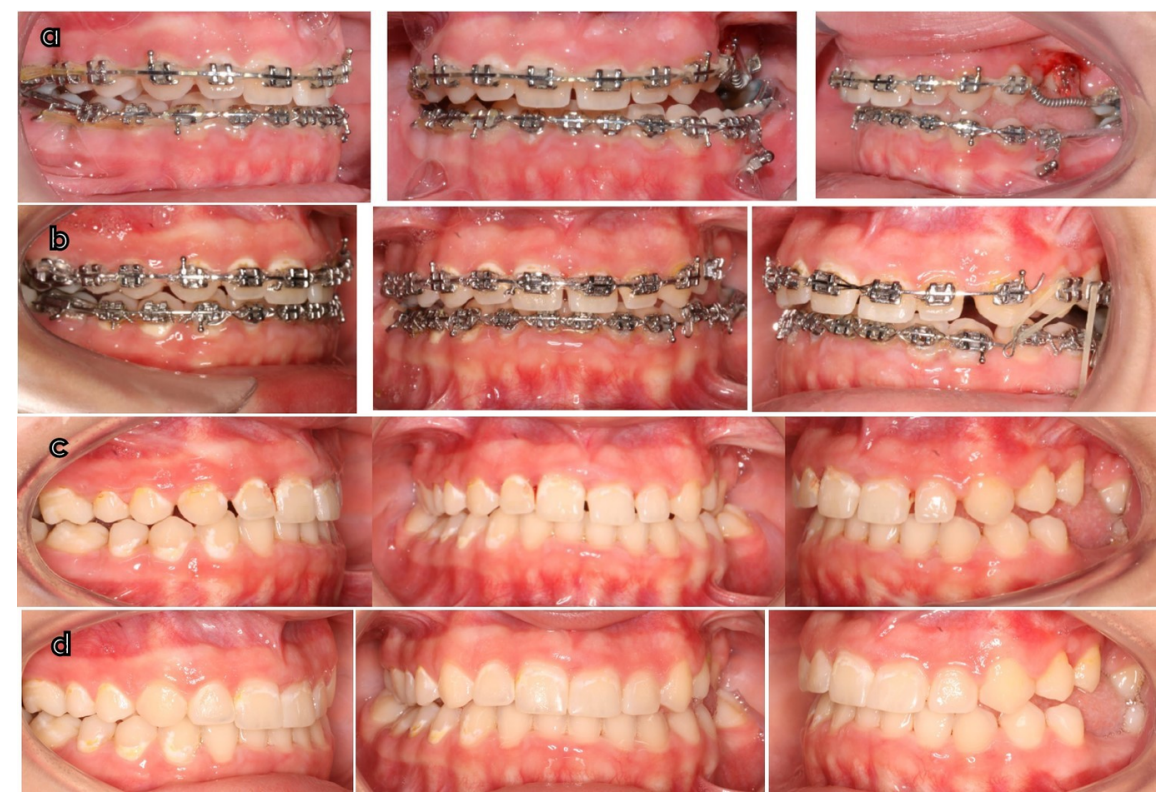

Figure 6: a, b: Interarch traction to extrude the upper left second premolar. c: Intra-oral pictures at deband. d: Intraoral pictures after composite restorations.

Once the upper left second premolar erupted out of the oral mucosa, a TAD $(1.6 \times 8 \mathrm{~mm})$ was placed on the opposing arch to facilitate further traction using inter-arch elastics. ${ }^{22,23}$ Although traction was initiated for a couple of months, it was noticed that the \#25 became unresponsive to orthodontic forces. (Figure 6 a, b) Furthermore, even the right side became unresponsive to any kind of orthodontic force. In addition, any further diastema closure and occlusal settling was not possible either. Eventually, after achieving what could best be done using fixed orthodontic treatment for the patient, it was decided to deband the appliance. The remaining spaces were closed using composite restorations to provide better esthetics. (Figure $6 \mathrm{c}, \mathrm{d}$ )

\section{Treatment Results}

Post-treatment intra-oral photographs showed good alignment, a reasonable relationship between upper and lower teeth, and ideal overbite. A much more aesthetic and pleasing smile was achieved along with harmony between the upper and lower lips, lip competence, coincident dental midlines and no muscle or joint problems during the treatment. All the spaces on the right side were successfully closed but on the left side, most of the spaces remained on the upper and lower arch. (Figure 7) Post-treatment cephalometric analysis showed that the sagittal jaw relationship improved a lot (pre-SNA, 80.4; post-SNA, 81.5; pre-SNB, 76.9; post SNB, 79.3; pre-ANB, 3.5; post-ANB, 2.2) while the mandibular plane remained almost constant (pre-FMA, 28.64; post-FMA, 28.33). There was a reduction in the lower incisor inclination (pre-IMPA, 86.16; post-IMPA, 77.5) and an increase in the upper incisor inclination (pre-U1-SN, 98.32; post- U1-SN, 106.18). The overjet was increased (pre, 2; post 3.5) and overbite was corrected (pre, -0.6; post, 1.3). (Table 1; Figure 8) 


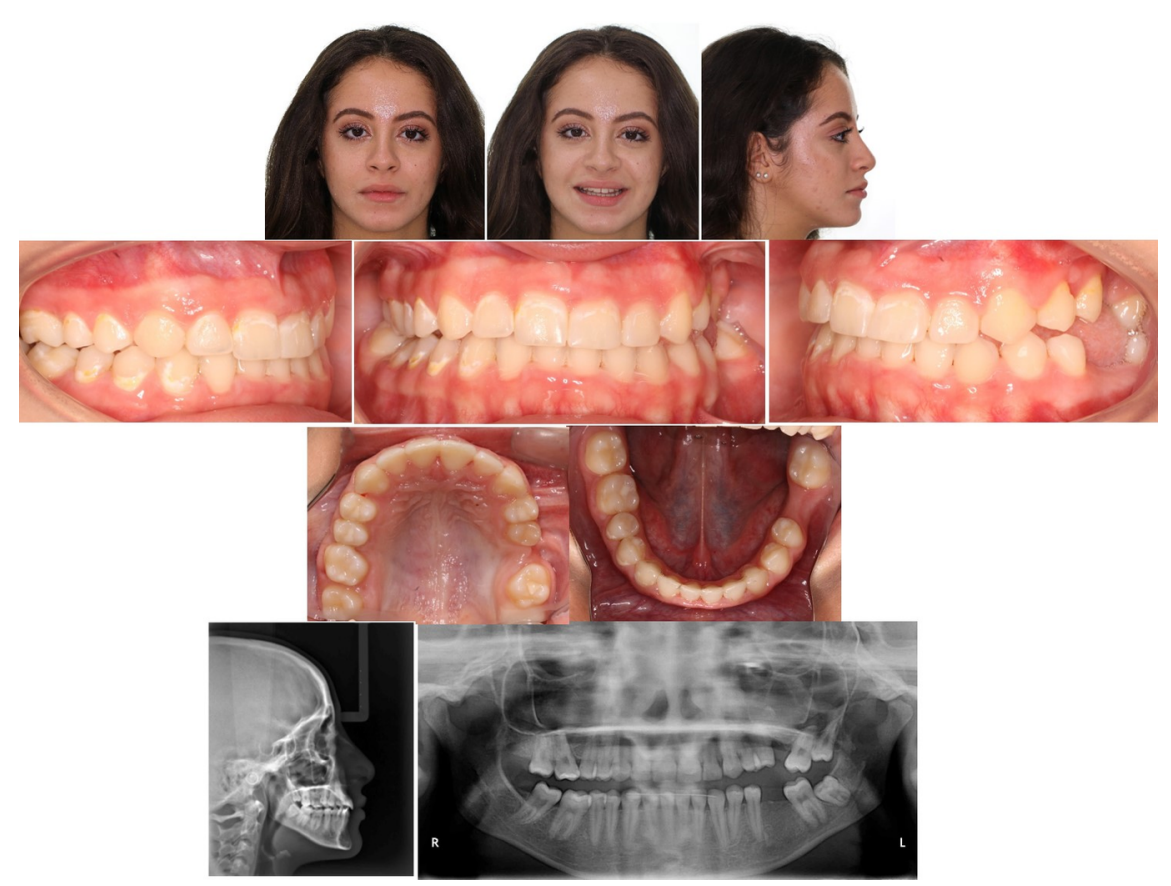

Figure 7: Post-treatment extra and intra-oral pictures with radiographs.

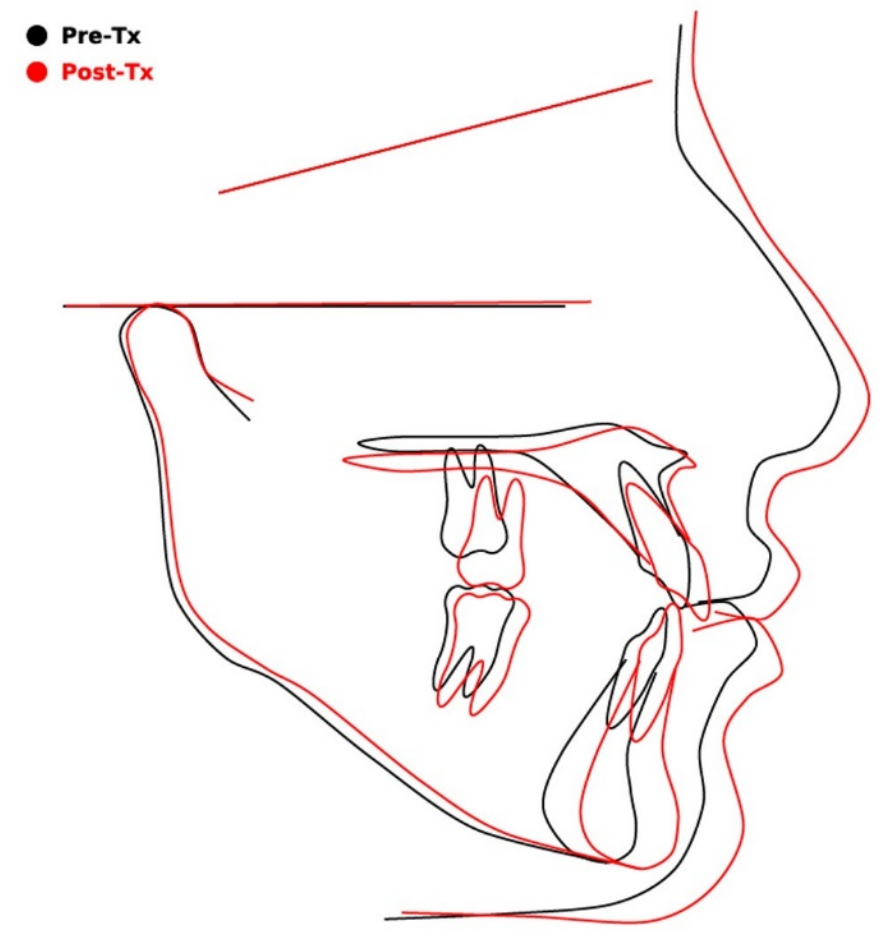

Figure 8: Superimpositions of the pre and post treatment cephalograms . 
The patient was provided with a fixed lingual retainer along with an Essix retainer on the upper and lower arch to maintain the corrected teeth positions. Routine check-ups were emphasized to closely monitor the treatment results.

\section{Discussion}

\section{Diagnostic challenges}

Diagnosis of PFE poses a significant challenge due to the high degree of variability involved with its clinical presentations. Familial and isolated cases also show a good amount of variations symptomatically. First, an obstruction must be ruled out. ${ }^{24}$ Following this, factors like an underlying supernumerary tooth, retained deciduous tooth, cystic lesions, bone calcifications, etc. must be ruled out. It may also be necessary to check for certain habits like a lateral tongue thrust or digit sucking that may predispose the formation of a posterior open bite by inhibiting the natural eruption of the posteriors. ${ }^{1,3}$

It may be imperative to rule out the possibility of a syndrome associated with such submerged/ unerupted teeth before proceeding with the treatment. Some syndromes associated are listed in Table $2{ }^{25}$

Table 2 Syndromes associated with failure of eruption. ${ }^{25}$

Table 2 Syndromes associated with failure of eruption. ${ }^{25}$ Cleidocranial dysplasia (OMIM 119600) Osteopetrosis (OMIM 16

\section{Treatment strategies}

Evidence suggests that any tooth affected with PFE will not respond to orthodontic forces. If the lateral open bite is to be corrected with orthodontic forces then it will lead to ankylosis of the affected teeth. This may act as an anchor and an extrusive force on the anchor may cause intrusion of adjacent teeth. Usually such attempts will worsen the existing open bite. To prevent such iatrogenics, it was decided not to involve the infra occluded first molar in the continuous mechanics. ${ }^{3,6,28}$

Treatment choice for PFE must be considered after evaluating the patient's age and the severity of PFE. For growing children, a conclusive treatment may not be possible until the vertical growth is completed. However a regular observation is necessary. In the case treated above, since the patient reported to us during growing stage, it was planned to close the other spaces and prepare the patient for a permanent prosthesis. In such growing patients, direct or indirect composite buildups could also ensure occlusal stability and preserve alveolar bone level until an implant placement is possible. ${ }^{29}$

In adult patients with only mild infraocclusion, it is prudent to accept the occlusion as it is and attempt no treatment. When affected teeth are partially erupted in the oral cavity, overlay crowns or overlay dentures can be considered as treatment options. In some cases removal of the affected tooth may be the treatment of choice. ${ }^{30}$ Yasumura and Sueishi ${ }^{31}$ reported a case of maxillary first molar that failed to erupt after fenestration and responded negatively to orthodontic forces. However, extraction of the affected first molar resulted in mesial migration and spontaneous eruption of the unerupted second molar. Further orthodontic treatment resulted in functional occlusion. A similar approach was followed in the above patient wherein we tried attempting protraction of second molars after extraction of first molars. It was successful on right side and failed on the left side.

Single tooth osteotomies have been promising as an alternate approach to correct the open bite related to PFE. This along with immediate elastic traction will utilise the regional acceleratory phenomenon. Shirotaet al.$^{32}$ reported a case of 24 year old male with unilateral posterior open bite secondary to PFE of maxillary premolars and molars. The patient was treated successfully with segmental osteotomy along with alveolar distraction. An alternative orthodontic treatment approach is to employ a segmented mechanics and avoid continuous arch wire and leaving the infra-occlusion and related open bite in the molar region uncorrected.

\section{Conclusion}


When faced with failure of eruption, it is important to have a hawk's eye while diagnosing and treating the patient. A careful observation of the presentation and the responses of teeth during treatment is very vital. We must be mindful of the true aetiology, given the similar clinical presentations of PFE, MFE and impactions. Impacted teeth should erupt once the physical obstruction is removed, however, teeth affected by PFE and MFE will not. It is important to remember that applying orthodontic traction to teeth affected by PFE will not be successful and, indeed, may cause ankylosis. A multi disciplinary approach is required to treat such conditions. This correspondence highlights the relevant literature around eruption failures and demonstrates the treatment of a case of PFE that was treated to the best possible outcome.

\section{References}

1. Kjær I. Mechanism of human tooth eruption: review article including a new theory for future studies on the eruption process. Scientifica (Cairo). 2014;2014:341905. doi: 10.1155/2014/341905. Epub 2014 Feb 12. PMID: 24688798; PMCID: PMC3944225.

2. Vijesh, Prashanth Kamath, Arun Kumar BR, Rajat Scindhia, Raghuraj MB.Primary eruption failure: A review. Int $J$ Appl Dent Sci2015;1(4):149-151.

3. Bhuvaneswarri J, Chandrasekaran SC. Failure of Eruption of Permanent Tooth. Int J Appl Basic Med Res. 2018 Jul-Sep;8(3):196-198. doi: 10.4103/ijabmr.IJABMR_366_17. PMID: 30123755; PMCID: PMC6082007.

4. Proffit WR, Vig KW. Primary failure of eruption: a possible cause of posterior open-bite. Am J Orthod. 1981 Aug;80(2):173-90. doi: 10.1016/0002-9416(81)90217-7. PMID: 6943937.

5. Frazier-Bowers SA, Hendricks HM, Wright JT, Lee J, Long K, Dibble CF, Bencharit S. Novel mutations in PTH1R associated with primary failure of eruption and osteoarthritis. J Dent Res. 2014 Feb;93(2):134-9. doi: 10.1177/0022034513513588. Epub 2013 Dec 3. PMID: 24300310; PMCID: PMC3895335.

6. Shivakumar GC, Srivastava A, Shivakumar S. Primary Failure of Eruption: A Cause of Posterior Open Bite. Int J Clin Pediatr Dent. 2019 Jul-Aug;12(4):360-361. doi: 10.5005/jp-journals-10005-1646. PMID: 31866725; PMCID: PMC6898881.

7. Mc Cafferty J, Al Awadi E, O'Connell AC. Case report: Management of severe posterior open bite due to primary failure of eruption. Eur Arch Paediatr Dent. 2010 Jun;11(3):155-8. doi: 10.1007/BF03262733. PMID: 20507816.

8. Hanisch M, Hanisch L, Kleinheinz J, Jung S. Primary failure of eruption (PFE): a systematic review. Head Face Med. 2018 Mar 15;14(1):5. doi: 10.1186/s13005-018-0163-7. PMID: 29544499; PMCID: PMC5856369.

9. Milani MS, Kuijpers MA. Primair falen van eruptie: diagnostiek, behandeling, casuïstiek en literatuuroverzicht [Primary failure of eruption: diagnostics, treatment, casus and review of literature]. Ned Tijdschr Tandheelkd. 2014 Apr;121(4):227-32. Dutch. PMID: 24881264.

10. Łyczek, J., \& Antoszewska, J. (2013). Primary Failure of Tooth Eruption - Etiology, Diagnosis and Treatment. Dental and Medical Problems, 50 , 349-354.

11. Frazier-Bowers SA, Koehler KE, Ackerman JL, Proffit WR. Primary failure of eruption: further characterization of a rare eruption disorder. Am J Orthod Dentofacial Orthop. 2007 May;131(5):578.e1-11. doi: 10.1016/j.ajodo.2006.09.038. PMID: 17482073.

12. Decker E, Stellzig-Eisenhauer A, Fiebig BS, et al. PTHR1 loss-of-function mutations in familial, nonsyndromic primary failure of tooth eruption. Am J Hum Genet 2008;83:781-6.

13. Grippaudo C, Cafiero C, D'Apolito I, Re A, Genuardi M, Chiurazzi P, Frazier-Bowers SA. A novel nonsense PTH1R variant shows incomplete penetrance of primary failure of eruption: a case report. BMC Oral Health. 2019 Nov 15;19(1):249. doi: 10.1186/s12903-019-0944-9. PMID: 31730001; PMCID: PMC6858648.

14. Frazier-Bowers SA, Simmons D, Wright JT, Proffit WR, Ackerman JL. Primary failure of eruption and PTH1R: the importance of a genetic diagnosis for orthodontic treatment planning. Am J Orthod Dentofacial Orthop. 2010 Feb;137(2):160.e1-7; discussion 160-1. doi: 10.1016/j.ajodo.2009.10.019. PMID: 20152661. 
15. Kanno CM, de Oliveira JA, Garcia JF, Roth H, Weber BH. Twenty-year follow-up of a familial case of PTH1R-associated primary failure of tooth eruption. Am J Orthod Dentofacial Orthop. 2017 Mar;151(3):598-606. doi: 10.1016/j.ajodo.2016.09.012. PMID: 28257744.

16. Roth H, Fritsche LG, Meier C, Pilz P, Eigenthaler M, Meyer-Marcotty P, Stellzig-Eisenhauer A, Proff P, Kanno CM, Weber BH. Expanding the spectrum of PTH1R mutations in patients with primary failure of tooth eruption. Clin Oral Investig. 2014;18(2):377-84. doi: 10.1007/s00784-013-1014-3. Epub 2013 Jun 15. PMID: 23771181.

17. Gama A, Maman L, Vargas-Franco JW, et al. Primary Retention of Molars and RANKL Signaling Alteration during Craniofacial Growth. J Clin Med. 2020;9(4):898. Published 2020 Mar 25. doi:10.3390/jcm9040898

18. Deffrennes, D. and J. Cohen-Levy. "Primary Failure of Eruption (PFE) and ankylosis of permanent molars: the surgeon's experience." Journal of Dentofacial Anomalies and Orthodontics 18 (2015): 407.

19. Jain U, Kallury A, Rao DD, Bharti HV. Primary failure of eruption (PFE). BMJ Case Rep. 2015 Apr 1;2015:bcr2015209703. doi: 10.1136/bcr-2015-209703. PMID: 25833913; PMCID: PMC4401965.

20. Mubeen S, Seehra J. Failure of eruption of first permanent molar teeth: a diagnostic challenge. J Orthod. 2018 Jun;45(2):129-134. doi: 10.1080/14653125.2018.1462902. Epub 2018 Apr 16. PMID: 29659339.

21. Benjamin M, Kate P, Samantha H. Primary failure of eruption - a review and case report. Orthodontic Update 2019 12:4, 140-144

22. Venugopal A. Interarch traction for impacted canines. APOS Trends Orthod 2020;10(1):60-1.

23. Venugopal A, Vaid NR. Interarch Traction Strategy for Palatal Cuspid Impactions. J Contemp Dent Pract. 2020 Dec 1;21(12):1408-1411. PMID: 33893268.

24. Sharma G, Kneafsey L, Ashley P, Noar J. Failure of eruption of permanent molars: a diagnostic dilemma. Int J Paediatr Dent. 2016;26 :91-99. doi: 10.1111/ipd.12163.

25. Sofia Ahmad, Dirk Bister, Martyn T. Cobourne, The clinical features and aetiological basis of primary eruption failure, European Journal of Orthodontics, Volume 28, Issue 6, December 2006, Pages 535540, https://doi.org/10.1093/ejo/cj1033

26. Parisay I, Kebriaei F, Varkesh B, Soruri M, Ghafourifard R. Management of a severely submerged primary molar: a case report. Case Rep Dent. 2013;2013:796242. doi: 10.1155/2013/796242. Epub 2013 Apr 22. PMID: 23819069; PMCID: PMC3654678.

27. Rhoads SG, Hendricks HM, Frazier-Bowers SA. Establishing the diagnostic criteria for eruption disorders based on genetic and clinical data. Am J Orthod Dentofacial Orthop 2013; 144: 194-202

28. Dixit UB, Jain MC. Primary failure of eruption, A review. Indian J Oral Health Res 2018;4:1-5.

29. Sehra B, Johnson J. The Prosthetic Management of an Infra-Occluded First Permanent Molar: Case Report. Dent Update. 2016 Jun;43(5):482-4, 486. doi: 10.12968/denu.2016.43.5.482. PMID: 27529916.

30. Pytlik W. Primary failure of eruption: a case report. Int Dent J. 1991 Oct;41(5):274-8. PMID: 1937846.

31. Yasumura T, Sueishi K. Posterior Open Bite Due to Failure of Maxillary Molar Eruption. Bull Tokyo Dent Coll. 2016;57(4):281-290. doi: 10.2209/tdcpublication.2016-0800. PMID: 28049976.

32. Shirota T, Hishida M, Yamaguchi T, Kurabayashi H, Maki K, Shintani S. Posterior maxillary segmental distraction for the treatment of severe lateral open bite caused by primary failure of tooth eruption: A case report. J Oral Maxillofac Surg Med Pathol 2013;25:39-42. 